\title{
ALCANCE DE LA ACCION PROTECTORA DE LA SEGURIDAD SOCIAL FRENTE A LAS LLAMADAS UNIONES DE HECHO
}

\author{
Fernando Manrique López \\ Catedrático de Derecho del Trabajo de la Universidad de Deusto
}

Sumario: I. La libre designación de beneficiarios en los sistemas complementarios de la Seguridad Social. A) El carácter complementario de las Prestaciones. B) El carácter voluntario de las Prestaciones. II. Nivel voluntario-libre. III. El Juego de la Legislación civil.

Es cada vez más frecuente que se planteen las cuestiones relativas a la posibilidad de designar beneficiario para el caso de que fallezca un titular de la relación jurídica de la Seguridad Social, antes de llegar al momento de la jubilación, lo que tiene particular importancia en los supuestos de personas separadas o divorciadas que desean favorecer a sus actuales parejas, de hecho o de derecho y/o a sus hijos y, a tal efecto, conviene examinar las cuestiones que se exponen a continuación:

\section{La libre designación de beneficiarios en los sistemas complementarios de la Seguridad Social}

El sistema público de Seguridad Social, frente a la ordenación de los seguros privados, no contempla, como es conocido, la posibilidad de designar beneficiarios para la percepción de las prestaciones devengadas a la muerte del causante, estableciendo un sistema predeterminado de causantes y beneficiarios ligados por vínculos familiares y requisitos adicionales, cuya amplia problemática ha tenido una gran repercusión jurisprudencial.

Los sistemas complementarios de Seguridad Social, amparados, como el Sistema Público, en el artículo 41 de la Constitución Española tienen una regulación dispersa que complica el análisis de su régimen 
jurídico y la solución de problemas concretos como el que nos ocupa pues muchas veces el mecanismo de gestión utilizado (seguro privado, plan de pensiones, mutualidad, fondos internos, etc.) se torna decisivo a estos efectos.

De la regulación legal básica, constituida hoy por el texto refundido de la Ley General de la Seguridad Social aprobado por Real Decreto legislativo 1/1994, de 20 de junio, se deduce (artículos 191 y siguientes) que las empresas pueden mejorar directamente las prestaciones del Régimen General de la Seguridad Social, costeándolas a su exclusivo cargo y podrán gestionarlas directamente, a través de la Administración de la Seguridad Social, Fundaciones Laborales, Montepíos y Mutualidades de Previsión Social o Entidades aseguradoras de cualquier clase. Establece el párrafo segundo del artículo 192:

«No obstante el carácter voluntario, para los empresarios, de la implantación de las mejoras a que este artículo se refiere, cuando al amparo de las mismas un trabajador haya causado el derecho a la mejora de una prestación periódica, este derecho no podrá ser anulado o disminuido, si no es de acuerdo con las normas que regulan su reconocimiento».

Como han declarado nuestros Tribunales (en este sentido, Sentencia del Tribunal Superior de Justicia del País Vasco de 18 de enero de 1991, Actualidad Laboral, R. 650), las mejoras otorgadas por las empresas, constituyen pactos u obligaciones unilaterales asumidas por las mismas, «que con el transcurso del tiempo y su aplicación efectiva han venido a convertirse en un negocio jurídico de comportamiento en el que la adhesión de los trabajadores implica su aceptación, resultando encuadrable dicha aceptación en el régimen de asistencia y prestaciones complementarias libres a que se refiere el artículo 41 in fine de la Constitución Española, cuyo tenor permisivo implica, además de la posibilidad de un sistema protector ajeno a la organización del Estado, la viabilidad de un régimen de prestaciones complementarias establecido directamente por la empresa, o concertado con los trabajadores, sin sometimiento a las normas de homologación legal establecidas en la sección primera del Capítulo XII de la Ley General de la Seguridad Social».

En este sentido, es doctrina consolidada y aceptada por juristas y Tribunales que la voluntad unilateral, con más frecuencia la del empresario, es fuente de obligaciones, de manera que producida esta voluntad y exteriorizada de alguna de las muy diversas formas en que puede ser expresada, la misma vincula a su emisor y le compele a su cumplimiento voluntario o forzoso.

El establecimiento de estas obligaciones a cargo del empleador, configura, en general, el principio de respeto a las condiciones más be- 
neficiosas de origen contractual, conforme al cual estas condiciones son inatacables por el empresario y por las normas estatales y convencionales posteriores. La voluntariedad en su nacimiento permite a su creador dotarlas de una regulación específica a la que hay que estar, pero una vez creadas también su autor queda sujeto a sus normas.

$\mathrm{Si}$, de otra parte, tales prestaciones deben su nacimiento a la voluntad de las partes establecida en acuerdo individual o colectivo, tales fuentes de la relación laboral, en el sentido establecido en el artículo 3 del Estatuto de los Trabajadores, constituyen, con fuerza de obligar, derechos y obligaciones concernientes a la relación laboral.

En cualquier caso, tales obligaciones en materia de previsión social, ha declarado la Sentencia del Tribunal Superior de Justicia del País Vasco de 18 de enero de 1991, que reiteramos con posterioridad, no «pueden calificarse como constitutivas de mejoras complementarias de la Seguridad Social, al no haber seguido los trámites de homologación legal (artículo 181.2 de la Ley General de la Seguridad Social y artículo 14 de la Orden Ministerial de 28 de diciembre de 1966); tampoco resulta posible su consideración como condición más beneficiosa, que necesariamente debe formar parte de una relación laboral activa. En todo caso la vigencia y vicisitudes de la calificada como mejora voluntaria por la resolución combatida estaría sometida a las normas reguladoras de su reconocimiento (art. 182.2 de la Ley General de la Seguridad Social y artículo 13 de la Orden de 28 de diciembre de 1966), o lo que es lo mismo, a los términos de su concesión».

Sirvan las anteriores consideraciones para poner en suerte el problema y para establecer dos principios diferentes que nos servirán para avanzar en las cuestiones planteadas, a saber:

A) El carácter complementario de tales prestaciones tiende a integrar su régimen jurídico con el de las prestaciones de la Seguridad Social, con cuya legislación se tenderán a solventar jurisprudencialmente las posibles lagunas existentes.

Un ejemplo de lo dicho lo encontramos en la Sentencia de 15-10-96 del Tribunal Superior de Justicia de Canarias (A. 4270) que ante un supuesto de fallecimiento de un trabajador declara el derecho de la reclamante, divorciada con anterioridad del causante, a percibir la pensión de viudedad prevista en el Convenio Colectivo de la Banca Privada. Señala la sentencia:

«Recurre a través de un motivo único la demandada $\mathrm{BCH}$ en el que censura la infracción del artículo 41.1, a) del Convenio Colectivo de la Banca Privada porque entiende que la actora no es viuda, que sería la 
beneficiaria según el Convenio, pues estaba divorciada, debiendo entenderse por viuda la que estuviera unida matrimonialmente en el momento del óbito del causante. El motivo debe desestimarse por las siguientes razones:

a) Tal concepto, expuesto por la recurrente sería el correcto desde el punto de vista sociológico o usual pero no lo es jurídicamente a parte de la Ley del Divorcio, la cual permite a una persona contraer sucesivos matrimonio válidos, con lo que, a su muerte, subsistirían varios cónyuges todos viudos, ya que la citada Ley, aun con carácter provisional concede, en su disposición adicional n. ${ }^{\circ} 10.3{ }^{a}$ el derecho a la pensión de viudedad y demás derechos pasivos o prestaciones por razón de fallecimiento, a quien sea o haya sido cónyuge legítimo... con independencia de las causas que hubieran determinado la separación o el divorcio.

b) La recurrente parece referirse pues a la viuda, conviviente al momento del óbito del causante pero, desde la mencionada Ley, el requisito de convivencia a que se refería el artículo 160 de la Ley de Seguridad Social de 1974 no es exigible y en la práctica, hoy no aparece en el artículo 174 del Texto Refundido de 1994 habiendo sido apartado como tal requisito para la pensión en la Resolución de 23 de junio de 1989 de la Secretaría General para la Seguridad Social.

c) Las prescripciones legales sobre este extremo tienen que cumplirse, pese a que el artículo 41 sea una norma prevista por el Convenio Colectivo ya que éste no aparta expresamente el concepto legal, única forma en que podría prosperar el recurso».

B) El carácter voluntario de las prestaciones debe implicar el máximo respeto a la voluntad del empresario, si instituyó las medidas unilateralmente o de las partes, si se pactaron en contrato o convenio colectivo.

Ejemplo de la aplicación de este principio y de las dificultades de interpretación que se producen en tales supuestos en que interviene además la legislación civil, lo encontramos en la Sentencia del Tribunal Superior de Justicia de Cataluña de 4 de mayo de 1995 (A. 1939) que ante un supuesto de indemnización por fallecimiento aplica la normativa de Seguridad Social porque hay una remisión expresa del Convenio Colectivo. Señala la indicada Sentencia:

«La interpretación que propugna el recurrente de concepto de "beneficiario" contenida en el artículo 24 de citado Convenio ya le fue negada tácitamente en la sentencia de esta Sala que declaró la nulidad de la primera sentencia, donde se le advertía que no bastaba con que acreditara ser padre del fallecido, sino que ademas debía quedar constancia de si es o no heredero y con carácter único o no, por lo que como míni- 
mo, en congruencia con la sentencia dictada por esta propia Sala, de haber acreditado ser heredero único del fallecido tal requisito podría haberse defendido que hubiera bastado para justificar su pretensión, y en el supuesto de haber acreditado ser heredero, pero no único, debería haberse posibilitado la llamada a juicio de los restantes herederos pues la indemnización es única para todos los posibles beneficiarios.

Sin embargo, el actor no sólo no acredita su condición de heredero, sino que de lo actuado se deduce que existen otras personas, como mínimo la madre y la hermana del fallecido que no son parte en las actuaciones y que pudieran tener los requisitos precisos para tener derecho a la prestación complementaria, aunque el actor no lo ostentara, personas de las que el demandante no ostenta su representación, ni siquiera alega actuar en beneficio de ellas, y no justifica que hubieran renunciado a sus posibles derechos.

Pero, con independencia de ello, es lo cierto que en el referido artículo 24 del Convenio se establece que la indemnización se abonará a los beneficiarios del fallecido, de acuerdo con lo previsto en las normas de la Seguridad Social y no a cualquier pariente o a todos ellos conjuntamente por el sólo hecho de serlo y con independencia de que ostenten o no derechos sucesorios de cualquier naturaleza sobre los posibles bienes y derechos del causante a tenor de las diversas legislaciones civiles que pudieran resultar aplicables

Acudiendo a la legislación de la Seguridad Social para que el padre del trabajador fallecido pueda considerársele beneficiario de posibles prestaciones de ella derivadas exigiría como presupuesto legal básico del artículo 162.1 de la Ley General de la Seguridad Social de 1974, la previa prueba por parte del solicitante de su dependencia económica del causante, remitiéndose, en cuanto ahora nos afecta, para la determinación de las restantes condiciones para su concesión a los Reglamentos generales de dicha Ley. Y en el artículo 22.1.2) de la Orden de 13 de febrero de 1967, por la que se establecen normas para la aplicación y desarrollo de las prestaciones de muerte y supervivencia del Régimen General de la Seguridad Social, se establece el derecho a prestaciones en favor de familiares con relación a los padres del fallecido siempre que: a) sean viudos; b) convivieran con el causante y a sus expensas, al menos con dos años de antelación al fallecimiento de aquél o desde la muerte del familiar con el que convivieran, si ésta hubiera ocurrido dentro de dicho período, c) que no tengan derecho a pensión del Estado, Provincia o Municipio o a prestaciones periódicas de la Seguridad Social, y d) que carezcan de medios de subsistencia y no queden familiares con obligación y posibilidad de prestarles alimentos, según la legislación civil».

Puede por lo tanto concluirse en lo siguiente:

1. El régimen complementario de la Seguridad Social ha de girar necesariamente sobre la estructura establecida para el nivel bá- 
sico, por exigirlo la Ley de forma precisa, cuando señala que la protección que otorga el sistema de la Seguridad Social tiene el carácter de mínimo y obligatorio para las personas incluidas en su campo de aplicación.

2. ${ }^{\circ}$ Esta protección puede ser mejorada en la forma establecida en la ley.

3. ${ }^{\circ}$ Queda prohibida la negociación colectiva en materia de Seguridad Social más allá de lo que signifique el establecimiento de las mejoras a que se refiere el punto segundo.

En consecuencia, esto significa que el régimen complementario de la Seguridad Social ha de partir de la estructura protectora del nivel básico, y suponer una hiperprotección respecto de los mismos sujetos a que se contrae el régimen básico, en relación con idéntica Acción Protectora.

Si las partes deseasen establecer cualquier otra suerte de beneficios, distintos de aquellos que supongan una mejora de la Acción Protectora del nivel básico, o para con respecto a sujetos protegidos, diferentes a aquellos que describe y reconoce como tales el campo de aplicación del Sistema, no estaremos ante un régimen complementario de la Seguridad Social, sino ante un régimen voluntario y libre que queda más allá del alcance del nivel de protección admitido por la ley dentro de lo que sea Seguridad Social.

Ante la hipótesis de que pudiera establecerse alguna suerte de mecanismos de protección para sujetos diferentes a aquellos a que se refiere la legislación de Seguridad Social, o respecto de una suerte de Acción Protectora distinta a la recogida como mínima y obligatoria por la legislación de la Seguridad Social, en cuanto a su sistema de protección propio, ha de entenderse que los efectos atribuidos por la jurisprudencia al binomino nivel básico-nivel complementario, podrán ser de discutible aplicación a esa suerte de protección voluntaria y libre, que haya nacido al margen de lo que establece la ley, para admitir el nacimiento de régimenes complementarios de mejora de la Acción Protectora básica de la Seguridad Social.

En particular nos referimos a lo que significa la consideración de la identidad de natualeza jurídica, que la jurisprudencia del Tribunal Supremo ha reconocido para con la Seguridad Social complementaria, respecto de la Seguridad Social básica, en el bien entendido sentido de que esa abundante doctrina de nuestro Tribunal Supremo ha señalado que, si se encuentra correctamente constituido un régimen complementario de la Seguridad Social, la naturaleza jurídica de las prestaciones nacidas en su seno, así como de las relaciones jurídicas origen de las mis- 
mas, participan de una identidad plena con la naturaleza jurídica de lo que resulta ser, por imperativo de la ley, el nivel básico mínimo y obligatorio.

Serían numerosos los efectos a que podríamos hacer referencia sobre este particular. Baste, no obstante, mencionar, a título enunciativo, que el régimen relativo a la prescripción de acciones y derechos, al régimen de embargo de prestaciones, a la mecánica de concurrencia y compatibilidad de prestaciones, o al tratamiento fiscal de éstas. Solamente si se ha constituido un régimen complementario de la Seguridad Social de acuerdo con la ley, la normativa reguladora de estas cuestiones (prescripción, fiscalidad, etc.) será aplicable a las mejoras así nacidas.

Por el contrario, si las partes establecen una mecánica de protección distinta de la que se corresponde con la Acción Protectora del nivel básico, mínimo y obligatorio, o si han acordado el reconocimiento de derechos en favor de beneficiarios que no ostenten la condición de tales en el nivel citado (mínimo y obligatorio), no podrán pretender el mismo tratamiento fiscal, de concurrencia de pensiones o cualquier otro, a que nos hemos referido anteriormente, previsto para el nivel básico, con las consecuencias enormemente negativas que esto significa.

Nuestro legislador, al igual que el de los restantes países de Europa, no admite el establecimiento de una protección dentro de la Seguridad Social para las situaciones de hecho, lo cual ha sido refrendado por el Tribunal Constitucional, considerando que ello es absolutamente coherente con los principios informadores de todo aseguramiento.

No se trata de que el legislador persiga fines moralizadores de conductas sociales, pues en el ámbito de la Seguridad Social nunca lo ha hecho (basta recordar lo que supone el reconocimiento de pensiones de orfandad en favor de cualquier clase de hijos legítimos o ilegítimos, matrimoniales o extramatrimoniales, al margen de cualquier consideración social o moral). Se trata de que las más elementales normas de aseguramiento obligan a tener en cuenta para la protección situaciones de hecho contrastables. En su consecuencia, la ley no otorga protección a las llamadas parejas de hecho, al igual que no concede cobertura al desempleado de hecho, ni al inválido de hecho.

Las muy estimables fórmulas protectoras que quieran establecerse sobre este particular deberán llevarse a cabo, en tanto en cuanto, no se altere la estructura de nuestros Seguros Sociales, a través de la acción estatal de protección, por vía de cualquiera de las múltiples iniciativas, que, a tal efecto, puedan establecerse en las distintas leyes, pero insistimos, hoy por hoy, y en tanto que la Seguridad Social responda a los principios de aseguramiento, tales medidas deberán quedar fuera de la legislación propia de la Previsión Social. 
A tal efecto, y como resumen de lo hasta aquí expuesto, podemos señalar lo siguiente:

En realidad y verificando un exhaustivo estudio de la doctrina jurisprudencial existente al respecto, la cuestión aparece resuelta por el propio Tribunal Constitucional que en numerosas ocasiones se ha pronunciado al respecto obligado por el hecho de estar claramente involucrados en la materia que se debate derechos fundamentales como el principio de la libertad, el de igualdad o el derecho a la intimidad y principios generales del derecho como es el principio de seguridad jurídica, que como es sabido, parte de la transcendente idea de que el Derecho configura el marco de actuación en el que ciudadanos, legisladores y miembros del Poder Judicial han de regular sus relaciones con la seguridad de saber con certeza como ejercitar sus derechos y como cumplir con sus obligaciones y deberes legales, constituyéndose así la legalidad en el pilar de la seguridad jurídica.

Así el Tribunal Constitucional en su sentencia de 15 de noviembre de 1990, número 184/1990, resolvió una cuestión de inconstitucionalidad que una Magistratura de Trabajo elevó el 29 de julio de 1988 en relación con el entonces vigente artículo 160 de la Ley General de la Seguridad Social, hoy artículo 174 Texto Refundido de la Ley General de la Seguridad Social, y la disposición adicional décima, 2 de la Ley 30/1981, de 7 de julio por oposición a los artículos 10, 14 y 39 de la Constitución Española, cuestión que se suscitó en un proceso en el que una señora tras fallecer en septiembre de 1987 el hombre con quien había convivido más de cuarenta años, solicitó pensión de viudedad, que le fue denegada por el Instituto Nacional de la Seguridad Social por no existir vínculo matrimonial con el causante y no tener legalizada la situación, dándose la circunstancia que la señora solicitante de la pensión había contrarído matrimonio en el año 1939 con otra persona que según se dice había desaparecido durante la guerra civil, normas éstas que se analizan por el Tribunal Constitucional en esta sentencia y en la que se basa el Instituto Nacional de la Seguridad Social en su resolución de 3 de diciembre de 1996 para denegar al actor la pensión que solicita.

Tal normativa exige por un lado la condición de viuda (o viudo, tras las Sentencias del Tribunal Constitucional 103/1983 y 104/1983, en criterio reiterado para preceptos conexos por las Sentencias del Tribunal Constitucional 42/1984, 253/1988, 144 y 176/1989 y 142/1990) del cónyuge causante para tener derecho a la pensión de viudedad, artículo 174, antes artículo 160 Texto Refundido de la Ley General de la Seguridad Social, y por otro lado condiciona el derecho a la pensión de viudedad de quienes no hubieran podido contraer matrimonio a que el 
fallecimiento de uno de ellos acaeciera con anterioridad a la vigencia de la Ley (Disposición adicional décima, 2, de la Ley 30/1981).

En su sentencia el Tribunal Constitucional con claridad señaló que por un lado para poder ser titular del derecho a la pensión de viudedad se requiere que el beneficiario de la misma hubiera contraído legítimo matrimonio con el (o la) causante Sentencias del Tribunal Constitucional 177/1985, 27/1986 y 260/1988, y de otro que la Ley 30/1981 que incide sobre esa situación no ha creado una nueva pensión distinta a la de viudedad, sino que se ha limitado a añadir a la causa de pedir existente (el vínculo matrimonial entre causante y beneficiario) una nueva causa basada en la convivencia extramatrimonial, pero sólo en y por las circunstancias recogidas en su disposición adicional décima, 2 (Sentencias del Tribunal Constitucional 27/1986).

Por ello concluye que este último precepto citado no incluye en su ámbito de aplicación todos los posibles supuestos de convivencia extramatrimonial, sino sólo aquellas uniones estables que tuvieran su causa en la imposibilidad de contraer matrimonio como consecuencia de la legislación anterior a la Ley 30/1981, en la que el divorcio era inexistente, y que, por lo tanto, no pudieron transformarse en vínculo conyugal. Es, pues, la imposibilidad, por impedimento legal, de contraer nuevas nupcias lo que constituye la base a la protección dispensada por el legislador a través de la norma en cuestión (Sentencia del Tribunal Constitucional 260/1988), por lo que la obtención de una pensión de viudedad se condiciona por la legislación vigente a la existencia de vínculo matrimonial entre causante y persona beneficiaria, exonerando de tal exigencia únicamente a quienes no pudieron contraer legítimo matrimonio por impedírselo la legislación anterior a la Ley 30/1981, ya siempre que el causante falleciera con anterioridad a dicha Ley nada impedía a los que convivían more uxorio transformar su relación en vínculo matrimonial. Si no lo hicieron pudiendo hacerlo, el legislador no otorga al supérstite el derecho a la pensión de viudedad.

El Tribunal Constitucional basó tal conclusión en las siguientes consideraciones:

-El libre desarrollo de la personalidad no resulta impedido ni coartado porque al supérstite de una unión de hecho la Ley no le reconozca una pensión de viudedad. El libre desarrollo de la personalidad podría resultar afectado, en su caso, si los poderes públicos trataran de impedir o de reprimir la convivencia more uxorio o de imponer el establecimiento del vínculo matrimonial, de manera que aquel tipo de convivencia no formalizada se viera expuesta a una gravosa y penosa suerte o a soportar sanciones le- 
gales de cualquier índole. Es evidente, se concluye, que el artículo 10.1 de la Constitución Española no puede servir en modo alguno de fundamento, por sí solo y aisladamente considerado, del derecho a percibir pensión de viudedad en favor de uno de los que convivían extramatrimonialmente cuando el otro fallece.

-Es claro que el artículo 39.1 de la Constitución Española no establece ni postula por sí solo una paridad de trato en todos los aspectos y en todos los órdenes de las uniones matrimoniales y no matrimoniales. Por ello no serán necesariamente incompatibles con el artículo 39.1 de la Constitución Española aquellas medidas de los poderes públicos que otorguen un trato distinto y más favorable a la unidad familiar basada en el matrimonio que a otras unidades convivencias, ni aquellas otras medidas que faciliten o favorezcan el ejercicio del derecho constitucional a contraer matrimonio (artículo 32.1 de la Constitución Española), siempre, claro es, que con ello no se coarte ni se dificulte irrazonablemente al hombre y la mujer que decidan convivir more uxorio, decisión ésta libremente adoptada por los sujetos de la unión de hecho y que diferencia el supuesto constituido por las medidas que afectan sólo a los integrantes de dicha unión respecto de otras previsiones normativas que tienen como destinatarios a los hijos, ya que éstos son iguales ante la ley con independencia de su filiación (artículo 39.2 de la Constitución Española) y a los cuales, habidos dentro o fuera del matrimonio, los padres deben prestar asistencia de todo orden (artículo 39.3 de la Constitución Española), precisamente, y entre otros motivos, porque su filiación y su condición de habidos dentro o fuera del matrimonio es el resultado de decisiones ajenas a los mismos.

-El matrimonio y la convivencia extramatrimonial no son situaciones equivalentes, siendo posible, por ello, que el legislador, dentro de su amplísima libertad de decisión, deduzca razonablemente consecuencias de la diferente situación de partida (Auto del Tribunal Constitucional 156/1987), y ello también respecto de las pensiones de viudedad, precisando a este propósito que la actual regulación de tales pensiones no vulnera lo dispuesto en el artículo 14 de la Constitución Española (en sentido análogo, Auto del Tribunal Constitucional 1021/1988 y 1022/1988 en relación con el subsidio de desempleo por responsabilidades familiares previsto en el artículo 13 de la Ley 31/1984, de 2 de agosto, de protección por desempleo), ni contiene discriminación alguna en función de una circunstancia social que tratae de excluir socialmente a las parejas que no hayan contraído matrimonio. 
-El matrimonio es una institución social garantizada por la Constitución, y el derecho del hombre y de la mujer a contraerlo es un derecho constitucional (artículo 32.1) cuyo régimen jurídico corresponde a la Ley por mandato constitucional (artículo 32.2). Nada de ello ocurre con la unión de hecho more uxorio, que ni es una institución jurídicamente garantizada ni hay un derecho constitucional expreso a su establecimiento. Tales diferencias constitucionales entre matrimonio y unión de hecho pueden ser legítimamente tomadas en consideración por el legislador a la hora de regular las pensiones de supervivencia.

-Es cierto que la posibilidad de optar entre el estado civil de casado o el de soltero está íntimamente vinculada al libre desarrollo de la personalidad (artículo 10.1 de la Constitución Española), de modo que el Estado no puede imponer un determinado estado civil. Pero lo que no reconoce la Constitución es un pretendido derecho a formar una unión de hecho que, por imperativo del artículo 14, sea acreedora al mismo tratamiento, singularmente, por lo que ahora importa, en materia de pensiones de la Seguridad Social, que el dispensado por el legislador a quienes, ejercitando el derecho constitucional del artículo 32.1 contraigan matrimonio y formalicen así la relación que, en cuanto institución social la Constitución garantiza, si bien es cierto también que el legislador podría extender a las uniones estables de hecho, al menos en determinadas condiciones, los beneficios de la pensión de viudedad. Extensión que en modo alguno resulta vedada por el artículo 14, ni encontraría obstáculos en los artículos 32 y 39 de la Constitución Española. El legislador dispone de un amplio márgen de libertad en la configuración del sistema de Seguridad Social y en la apreciación de las circunstancias socioeconómicas de cada momento a la hora de administrar recursos limitados para atender a un gran número de necesidades sociales. Pero que dicha extensión sea constitucionalmente admisible no implica que la opción contraria y en la actualidad vigente no lo sea.

-Esta conclusión no se altera por el hecho de que en otros supuestos muy distintos al de la pensión de viudedad el legislador haya equiparado al cónyuge la análoga relación de afectividad como se hace en los artículos 11 y 18 Código Penal, artículo 3 a) Ley Orgánica 6/1984, de 24 de mayo, de procedimiento de habeas corpus, artículo 10 de la L 5/1984, de 26 de marzo, de regulación del derecho de asilo y de la condición de refugiado, y con expresiones equivalentes, artículo 391.1 Ley Orgánica del Poder Judicial y artículo 101 Código Civil, preceptos que todo lo más son 
indicativos de que las relaciones permanentes de su afectividad análogas a la matrimonial comienzan a ser atendidas en determinados y peculiares casos y, dotadas de ciertos efectos por el ordenamiento jurídico, por ello, en sí mismo y por sí solo, y mucho menos por una pretendida exigencia del principio de igualdad, no fuerza a hacer lo mismo en el caso de la actual pensión de viudedad, como se hizo siguiendo la recomendación del Defensor del Pueblo, respecto del derecho a la asistencia sanitaria que se extendió, en efecto, por Resolución administrativa de 29 de diciembre de 1984, a la persona que, sin ser cónyuge del titular del derecho, conviva maritalmente con él, siempre que, por su dedicación al hogar, no pueda obtener la asistencia por sí misma mediante el ejercicio de una actividad retribuida, como clara tendencia hacia la universalización de las prestaciones de asistencia sanitaria, luego plasmada en el Real Decreto 1.088/1989, de 8 de septiembre, finalidad bien distinta de la perseguida con la pensión de viudedad.

En definitiva, el Tribunal Constitucional concluye (doctrina que se reitera en la Sentencia 126/1994), que si bien el legislador podría reconocer el derecho a una pensión de supervivencia idéntica a la de viudedad, al supérstite de la unión estable de hecho, en los supuestos y con los requisitos que en su caso se establecieran, el hecho de que el legislador en la actualidad no lo haya hecho así no lesiona en sí mismo el artículo 14 Constitución Española ni tampoco en su conexión con el artículo 39.1 del propio texto constitucional, doctrina ésta que aparece confirmada por las normas y los Convenios Internacionales que vinculan a España en los que igualmente exigen, como regla general, el previo vínculo matrimonial con el causante para tener derecho a las prestaciones por fallecimiento de aquél, como es el caso, señaladamente del Convenio número 192 de la Organización Internacional del Trabajo (OIT), relativo a la norma mínima de la Seguridad Social (ratificado por España el 17 de mayo de 1988), al que se refiere el artículo 12.2 de la Carta Social Europea.

Por otra parte, la posterior Sentencia del Tribunal Constitucional de 11 de diciembre de 1991, número 222/1992, determinó la inconstitucionalidad del artículo 58.1 de la Ley de Arrendamientos Urbanos en la medida en que excluye del beneficio de la subrogación arrendaticia a quien hubiera convivido de modo marital y estable con el arrendatario fallecido, sentencia que se refería a un supuesto de hecho diferente, y que contiene una doctrina no trasladable al supuesto que ahora nos ocupa, habiendo incluso aclarado tal posibilidad el propio Tribunal Consti- 
tucional que en el reciente Auto 232/1996 de 22 de julio, que inadmitió el recurso de amparo que una mujer formuló tras habérsele negado una pensión de viudedad después de haber convivido más de 70 años con quien erróneamente creía su marido por no haberse formalizado un matrimonio civil, rechazó la posibilidad de rectificar la doctrina sentada por el Tribunal Constitucional en su sentencia 1843/1990, para tener en cuenta la doctrina sentada en la sentencia 222/1992, ratificando así los criteros ya expuestos y relativos a la pensión de viudedad.

Atendidas las consideraciones suficientemente expuestas, en las que el propio Tribunal Constitucional con reiteración, ha señalado que la obtención de una pensión de viudedad se condiciona por la legislación vigente a la existencia de vínculo matrimonial entre causante y persona beneficiaria, exonerando de tal exigencia únicamente a quienes, no pudieron contraer legítimo matrimonio por impedírselo la legislación anterior a la Ley 30/1981, y siempre que el causante falleciera con anterioridad a la vigencia de dicha Ley, inexistencia de vínculo matrimonial que determina la corrección de la resolución del Instituto Nacional de la Seguridad Social recurrida por el actor.

El hecho de que en el caso del actor y del hombre con el que convivió como pareja durante una importante etapa de su vida, la imposibilidad de contraer matrimonio venga impuesta por la ley, no altera las conclusiones expuestas por el Tribunal Constitucional, sin que pueda ser amparable la pretensión de aplicación directa de la Constitución, sin que se altere el propio sistema de fuentes del ordenamiento jurídico (artículo 1.7 del Código Civil), según la doctrina del Tribunal Constitucional, que ha reiterado la plena constitucionalidad de la actual normativa de concesión de las pensiones por viudedad por no conculcar los principios de igualdad, no discriminación y libre desarrollo de la personalidad, y en definitiva supone no una interpretación de las normas conforme a los principios de analogía, que no la hay, o de interpretación según la realidad social del tiempo en que han de ser aplicadas conforme al artículo 3.1 del Código Civil (tampoco posible, no se puede pretender utilizar instituciones jurídicas cuyo origen y contenido tiene un perfil claro y una regulación precisa y aplicarlas a una realidad social distinta que no ha sido contemplada por el legislador, según refirió el Tribunal Constitucional en la sentencia 222/1992), salvo que en realidad se pretenda se creen derechos donde no lo hay, actuando indebidamente como legislador positivo.

Los condicionamientos y límites que, en virtud del principio de igualdad, pesan sobre el legislador se cifran en una triple exigencia, pues las diferenciaciones normativas habrán de mostrar, en primer lugar, un fin discernible y legítimo, tendrán que articularse, además en 
términos no inconsistentes con tal finalidad y deberán, por último, no incurrir en desproporciones manifiestas a la hora de atribuir a los diferentes grupos y categorías derechos, obligaciones o cualesquiera otras situaciones jurídicas subjetivas.

El matrimonio y la convivencia extramatrimonial no son situaciones equivalentes, siendo posible por ello que el legislador, dentro de su amplísima libertad de decisión, deduzca razonablemente consecuencias diferentes de la diferente situación de partida.

En definitiva, habrá de ser en su caso, el legislador quien decida proceder a la extensión de la pensión de viudedad, con los requisitos y en los términos que se consideren pertinentes, en aquellas convivencias heterosexuales que se valoren y estimen por el Poder Legislativo, teniendo en cuenta el contexto general que aquellas situaciones se producen, las circunstancias socioeconómicas, la disponibilidad de medios de financiación y las necesidades de los diversos grupos sociales, así como la importancia de las mismas, tal y como destaca la sentencia del Tribunal Supremo 65/1987.

Las anteriores argumentaciones nos sirven para señalar como conclusiones que, de una parte, las mejoras voluntarias exigen necesariamente una regulación adaptada a la normativa de Seguridad Social, que ante la existencia de una laguna legal la jurisprudencia tenderá, no obstante, a aplicar dicha normativa.

\section{Nivel voluntario-libre}

Sin perjuicio de lo establecido en el número anterior ha de señalarse que sí es posible el establecimiento de un nivel complementario voluntario y libre fuera del alcance del ámbito correspondiente a los regímenes complementarios de la Seguridad Social, y en este sentido, si así se estructurara, cabría la regulación de una suerte de aseguramiento pudiendo establecer un orden de beneficiarios distintos de la legislación civil y de la Seguridad Social.

En palabras de la Sentencia del Tribunal Superior de Justicia de Castilla y León de 28 de febrero de 1994 (A. 636), que tendremos ocasión de citar con posterioridad por resolver un supuesto en el que concurren casi todos los elementos del problema debatido:

«Los términos en que se halla redactado el convenio colectivo son absolutamente nítidos y no permiten albergar duda alguna acerca de la voluntad de los negociadores, acertando plenamente el Magistrado de instancia al sostener la necesidad de aplicación de la normativa vigente 
en materia de Seguridad Social y más concretamente el artículo 163 de la Ley General de la Seguridad Social de 1974 (artículo 177 del texto refundido aprobado en junio de 1994). En efecto, los artículos 21 y 182 de la Ley de Seguridad Social permiten el establecimiento de mejoras de la Seguridad Social a cargo de las Empresas, las cuales, una vez establecidas, se entenderá que forman parte, a todos los efectos, de la acción protectora de la Seguridad Social (artículo 1.3 de la Orden Ministerial de 28 de diciembre de 1966). Claro es que los firmantes del Convenio, por tratarse de un complemento voluntario, pudieron establecer una prelación de beneficiarios distinta de las previstas en el Decreto de 30 de mayo de 1974, pero lo cierto es que el tenor del Convenio revela nítidamente, que las partes optaron, salvo decisión en contrario de cada trabajador individual, por remitirse a lo dispuesto en el Régimen Obligatorio de la Seguridad Social, régimen en el que se prescinde de forma absoluta de la condición de heredero y en el que (artículo 163 de la de 1974 y 177 del texto legal vigente) se reconoce la condición de beneficiarios a los viudos y huérfanos. Cierto que tal designación de beneficiarios está prevista para los supuestos de fallecimiento por accidente de trabajo y enfermedad profesional, pero no lo es menos que (artículo 4 del Código civil) resulta preciso acudir a la analogía cuando la norma no contemple el supuesto concreto de que se trate pero regule otro y entre ambos concurra identidad de razón, exigencia ésta indiscutible.»

Con ello queda consagrado la posibilidad de que pueda establecerse de acuerdo con la ley un nivel complementario voluntario y libre, al margen del complementario de la Seguridad Social básica, de modo que, ante tal hipótesis, las partes puedan establecer una prelación de beneficiarios distinta de la que ofrece la Seguridad Social.

\section{El Juego de la Legislación Civil}

Puede plantearse que la designación de beneficiarios libremente realizada por el causante puede eludir la normativa civil sobre sucesiones y representar un fraude para los herederos. El informe del Director de Trabajo y Seguridad Social del Gobierno Vasco de 10 de julio de 1997, elaborado a instancias de una Entidad de Previsión Social Voluntaria, entiende que la falta de normativa concreta en la Ley 25/1983 de 27 de octubre y Decreto 87/1984 de 20 de febrero (sobre Entidades de Previsión Social Voluntarias del País Vasco) y en la legislación estatal de planes y fondos de pensiones podría llevar a la aplicación de la normativa civil (Capítulo IV del Título III del Código Civil), lo que limitaría la libertad de designación de beneficiarios, por el juego de las legí- 
timas, con la consecuente paralización de las Entidades de Previsión que antes de pagar los derechos consolidados habrían de cerciorarse del monto total del caudal relicto y no perjudicar así las legítimas. Por esta razón opta por aplicar, análogicamente (ex artículo 4.1 del Código Civil) las normas de Ordenación y Supervisión de los Seguros Privados y concretamente los artículos 84 y 88 de la Ley del Contrato de Seguro que proclaman el derecho a la libre designación de beneficiarios y el deber del asegurador de entregar la prestación al beneficiario designado, aun contra las reclamaciones de los herederos legítimos y acreedores de cualquier clase del tomador del seguro.

Dicha tesis es desde luego muy razonable, aun cuando tratándose de asunto delicado, en el que juegan tres distintas normativas (Seguridad Social, Seguros y Civil) a las que puede acudirse análogicamente, cada una con diferente regulación, seguirá siendo cuestión discutible jurídicamente en la que no caben afirmaciones absolutas. No obstante, coincidimos con la conclusión del informe comentado, esto es con la posibilidad de designar beneficiario, aun contra la legislación civil sobre sucesiones, pero ello siempre que se haga fuera del régimen complementario de la Seguridad Social establecido como mejora de la Acción Protectora del nivel mínimo básico y obligario, sirviendo para amparar tal tesis la ausencia de normativa específica en el ámbito de las mejoras voluntarias y en el del mecanismo de gestión utilizado (Entidades de Previsión Social Voluntarias sometidas a la normativa del País Vasco), la existencia de norma en ámbito distinto (Seguros) cuyo supuesto de hecho comparte la identidad de razón y la existencia de norma concreta en el sector de los planes de pensiones, también aplicable analógicamente, pues el n. ${ }^{\circ} 6$ del art. 8 de la Ley 8/1987, de 8 de junio, de planes y fondos de pensiones, en la redacción introducida por la Ley 30/1995, de 8 de noviembre, de ordenación de los seguros privados, establece lo siguiente:

«Las contingencias por las que se satisfarán las prestaciones anteriores podrán ser:

a) Jubilación o situación asimilable. Reglamentariamente se determinarán las situaciones asimilables.

De no ser posible el acceso del beneficiario a tal situación la prestación correspondiente sólo podrá ser percibida al cumplir los sesenta años de edad.

b) Invalidez laboral total y permanente para la profesión o absoluta y permenente para todo trabajo y la gran invalidez.

c) Muerte del partícipe o beneficiario, que pueden generar derecho a prestaciones de viudedad, orfandad, o en favor de otros herederos o personas designadas. No obstante, en el caso de 
muerte del beneficiario que no haya sido previamente partícipe, únicamente se pueden generar prestaciones de viudedad u orfandad.»

A idéntica conclusión llega, como vimos, la Sentencia de 28 de febrero de 1995 del Tribunal Superior de Justicia de Castilla y León, que ante la reclamación formulada por la esposa divorciada de un trabajador que pretendía obtener una indemnización por fallecimiento que ya había percibido el padre heredero de la víctima, condena a la Empresa a realizar el pago a la demandante. Precisamente resuelve la controversia, en sus aspectos civiles, con fundamento en el artículo 659 del Código Civil:

«La disposición adicional décima de la Ley de 7 de julio de 1981 de modificación del Código Civil en materia de matrimonio, expresamente dispuso la subsistencia del derecho a las prestaciones de Seguridad Social en favor de los viudos en los supuestos de separación, previsión legal ahora contemplada en los artículos 177 y 174 del Texto legal vigente de Seguridad Social, que obliga a estimar correcto el proceder del Magistrado de instancia al atribuir a la actora la condición de beneficiaria de la prestación reclamada, sin que quepa aceptar la tesis de que el importe de tales indemnizaciones (al margen de la normativa reguladora del impuesto de sucesiones) forme parte del caudal hereditario, pues el artículo 659 del CC no permite incluir en la masa de la herencia derechos patrimoniales que no pertenecían al fallecido, en razón, precisamente, de haber nacido por razón del óbito.»

El informe de la Dirección de Trabajo y Seguridad Social del Gobierno Vasco a que nos referimos con anterioridad entiende que la Entidad que abona al designado beneficiario, cumpliendo la voluntad del asociado, queda liberada de toda responsabilidad y los posibles herederos legítimos no quedan desprotegidos puesto que podrán repercutir contra dicho beneficiario si lo estiman en derecho. Se funda en el artículo 88 de la Ley del contrato de seguro, que aplica por analogía y que señala lo siguiente:

«La prestación del asegurador deberá ser entregada al beneficiario, en cumplimiento del contrato, aun contra las reclamaciones de los herederos legítimos y acreedores de cualquier clase del tomador del seguro. Unos y otros podrán, sin embargo, exigir al beneficiario el reembolso del importe de las primas abonadas por el contratante en fraude de sus derechos».

Podemos añadir que tal tesis entronca con la legislación civil, pues el art. 1.162 del Código Civil señala que «el pago deberá hacerse a la 
persona en cuyo favor estuviese constituida la obligación, o a otra autorizada para recibirla en su nombre» y el art. 1.164 del Código Civil, establece que «el pago hecho de buena fe al que estuviere en posesión del crédito liberará al deudor». Luego la Entidad de Previsión habrá de cumplir las prescripciones estatutarias que le obligan y la voluntad del causante si la misma se constituye en la fuente de la obligación.

La propia Sentencia del Tribunal Superior de Justicia de Castilla y León de 28 de febrero de 1995, que ya hemos citado, condenó a la empresa a abonar a la viuda reclamante la indemnización que ya había pagado al padre heredero, con los siguientes argumentos:

«Ciertamente el artículo 1.164 del CC reputa liberado al deudor que pagare de buena fe al que estuviere en posesión del crédito, pero no es menos cierto que tal situación no concurría en el caso del padre del fallecido, afirmación que resulta nítida si se tiene en cuenta que, conforme a lo anteriormente expuesto, el beneficiario de la prestación no es el heredero del fallecido sino su viuda, y que la existencia de ésta, así como su reclamación de la indemnización, era conocida por la empresa en el momento de hacerse el pago, circunstancias éstas que permiten negar la existencia de buena fe exigida por el precepto citado, pues tal requisito sólo concurre en el supuesto de que el deudor haya actuado con la diligencia exigible a quien actúa en el tráfico jurídico.

Indiscutible la obligación de la empresa de abonar a la hoy demandante el importe de la indemnización reclamada en autos, y no liberado el deudor por el pago hecho al heredero del trabajador fallecido, se está en el caso de revocar la sentencia de instancia en cuanto absolvió a la mencionada Sociedad, y también en cuanto al pronunciamiento condenatorio recaído sobre el padre del fallecido, y ello por la sencilla razón de que la acción de la demandante contra éste únicamente resultaría procedente en el supuesto de ejercicio de la acción subrogatoria del artículo 1.111 del Código Civil, y sobre la base del cobro de lo indebido, que no se dedujo en la demanda ni podría haberse actuado con éxito al no haberse ni tan siquiera alegado la inexistencia de bienes en el deudor suficientes para el cobro del crédito reclamado». 